The gulf between

the ideal type of a

learning organization

and the state of affairs

in typical bilateral

and multilateral

development agencies

remains huge.

Defining roadblocks,

however numerous

they may be, is half

the battle to removing

them - it might make

them part of the

solution instead of part of the problem.

\section{Overcoming Roadblocks to Learning $^{1}$ \\ Background}

Organizational learning is collective learning by individuals, and the fundamental phenomena of individual learning apply to organizations. However, organizational learning has distinctive characteristics concerning what is learned, how it is learned, and the adjustments needed to enhance learning. These owe to the fact that an organization is, by general definition, a collective whose individual constituents work to achieve a common goal from discrete operating and supporting units. Practices bring different perspectives and cultures to bear and shape data, information, and knowledge flows.

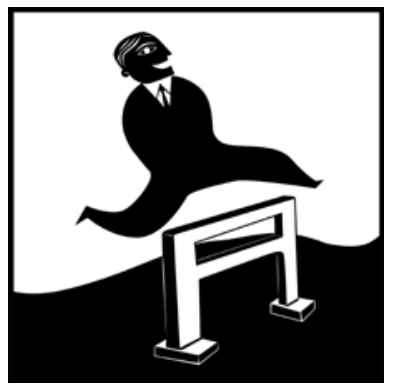

Political considerations are the most serious impediment to becoming a learning organization. However, by understanding more fully what obstacles to learning can exist in a complex organization in a complex environment, one can circumscribe the problem space and create enabling environments for a more positive future. Such environments would facilitate self-organization, exploration of the space of possibilities, generative feedback, emergence, and coevolution. They would create an explanatory framework and facilitate action.

An organization belongs on the sick list when promotion becomes more important to its people than accomplishment in the job they are in. It is sick when it is more concerned with avoiding mistakes than with taking the right risks, with counteracting the weaknesses of its members rather than with building on their strength. But it is sick also when "good human relations" become more important than performance and achievement ... The moment people talk of "implementing" instead of "doing" and of "finalizing" instead of "finishing," the organization is running a fever.

-Peter Drucker

These Knowledge Solutions draw in part from Goold, L. 2006. Working with Barriers to Organizational Learning. Available: www.bond.org.uk/pubs/briefs/olbarriers.pdf 


\section{Knowledge
Solutions}

\section{The Bias for Action}

The organizational context of nongovernment organizations seems to give more value to action than to reflection. An activist culture can lead to quick fixes that in the long term can exacerbate the problems faced if the second-order causes of the problems are not recognized and tackled. The forces that favor jumping into "solutions mode" include (i) time spent in inconclusive deliberations; (ii) the urgency of task; (iii) the felt need for action; (iv) avoidance of reflective observation, unclear concepts, and uncertainty of outcomes; and (v) fear of failure leading to avoidance of decisions. Figure 1 illustrates how these pressures reinforce the bias for action instead of encouraging reflection and inquiry. Process and task must be seen as interdependent, as should reflection and action.

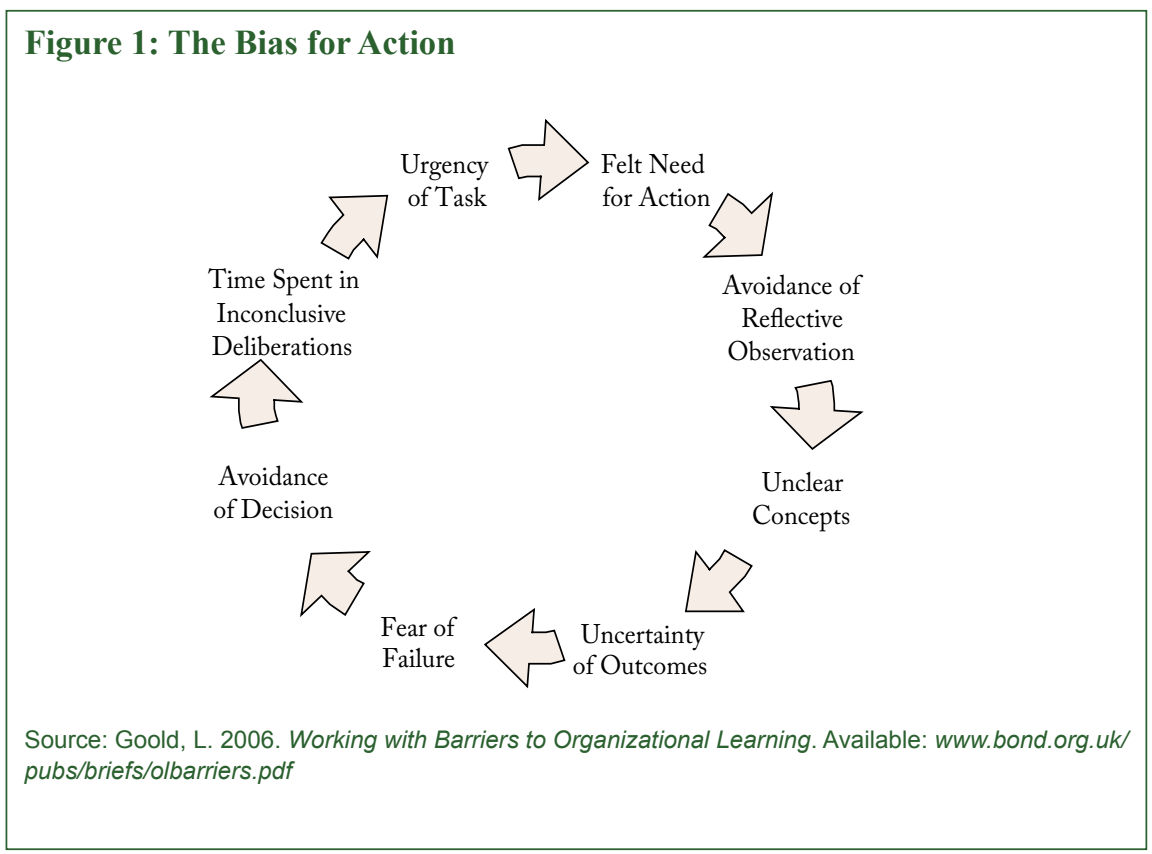

\section{Undiscussables}

Behind some pressures that reinforce the bias for action is inability to handle anxiety and fear, compounded by the defensive routines that are built in response. People faced with error, embarrassment, or threat will typically act to avoid these, make the avoidance undiscussable, and make its undiscussability undiscussable. They will do so because they assume that their actions will reduce the likelihood of a situation escalating further. Much energy can be wasted in avoiding controversy; however, it is not potential conflict but the avoidance of action to resolve conflict that causes problems. One approach to undiscussables is to invite speculation, perhaps with the help of a facilitator or with simple guidelines: What is the worst thing that might happen? What would happen if it did? The way to remain scared is to not find out what one is afraid of. Table 1 illustrates three types of organizational responses to error, only one of which assuages the fear of failure that biases action. 
Table 1: Organizational Responses to Error

\begin{tabular}{|c|c|c|}
\hline Self-Deceiving Response & Defeated Response & Learning Response \\
\hline \multicolumn{3}{|l|}{ Error Definition } \\
\hline $\begin{array}{l}\text { - Failure } \\
\text { Strategic Decision }\end{array}$ & - A force beyond control & - A source of information \\
\hline $\begin{array}{l}\text { The error is hidden or someone is } \\
\text { saddled with the blame. }\end{array}$ & $\begin{array}{l}\text { The error is talked about in } \\
\text { rich detail but no action is } \\
\text { taken. }\end{array}$ & $\begin{array}{l}\text { - The error is discussed candidly } \\
\text { and corrective actions are } \\
\text { attempted. }\end{array}$ \\
\hline \multicolumn{3}{|l|}{ Impact on Leadership } \\
\hline $\begin{array}{l}\text { The leadership is (partly) deceived } \\
\text { and thinks everything is going } \\
\text { exactly to plan. }\end{array}$ & $\begin{array}{l}\text { The leadership is } \\
\text { left impotent and the } \\
\text { organization becomes } \\
\text { immobilized. }\end{array}$ & $\begin{array}{l}\text { The leadership is able to } \\
\text { continuously draw on lessons } \\
\text { learned. }\end{array}$ \\
\hline
\end{tabular}

Source: Adapted from Korten, D., and R. Klauss, eds. 1984. People-Centered Development: Contributions Toward Theory and Planning Frameworks. West Hartford, Connecticut: Kumarian Press.

\section{Commitment to the Cause}

The individuals who are drawn to development work acknowledge a basic commitment to reducing poverty. From their perspective, they are altruistic and action oriented. Yet their commitment can become compulsivethe cause is never ending, and if they were to pause and reflect, they may question what they have really been doing. Some keep "doing" and suffer from exhaustion, cynicism, or burnout. They may also allow an element of self-righteousness to creep in. Hard work, high energy, and dedication to poverty reduction are not per se negative or unhealthy at the individual or collective level, but their meaning and purpose and one's attachment to them must be questioned with an open mind.

\section{Advocacy at the Expense of Inquiry}

In much aid work, more value appears to be given to advocating a position than inquiring about the view of beneficiaries. This gives little opportunity for new insights and concepts to emerge. Many of the universal practices and behaviors of dialogue and inquiry can help, such as the ability to suspend assumptions, listen to one another earnestly, give voice to what one really thinks, and respect difference. To improve the quality of everyday conversations and make better use of collective spaces for learning, there is an urgent need to develop the art of talking and thinking difIt is a strange trade that of advocacy. Your intellect, your highest heavenly gift is hung up in the shop window like a loaded pistol for sale. ferently together.

\section{Cultural Bias}

Western cultural assumptions have shaped development work, perhaps also the debates on organizational learning. They are apt to value outputs and outcomes over process, and show a predilection for linear, predictable causality (evidenced, for instance, by the design and monitoring framework, also known as logical framework 
analysis). ${ }^{2}$ East Asian cultures place more emphasis on discussing the problem at hand, after which those present will know what is needed without feeling locked into a specific decision. The rigidity of fixed assumptions apparent in aid agencies should be tempered by insights and concepts such as nonlinearity, edge of chaos, selforganization, emergence, and coevolution. ${ }^{3}$ At the village level, tools that have been found useful include storytelling, community theater, and participatory approaches. Learning Lessons in $A D B^{4}$ specifies other cultural roadblocks in the form of psychological and social factors.

\section{Practicing What Is Preached}

Some values and processes that development agencies promote, such as good governance and results-based management, are not practiced internally. At least this raises questions of integrity. If aid agencies reflected on the difficulty of learning in their organizations, they might promote it more sensitively and build absorptive capacity both in-house and elsewhere.

\section{The Funding Environment}

Funding that is tied to particular programs or projects - ironically often to capture "lessons learned"- does not encourage creative thinking and innovation. Nor does it pave the way for intraorganizational and interorganizational learning, let alone partnerships in developing countries. Second-order forms of learning can be developed without tying funding to prespecified outcomes, such as looking at the qualities and approaches needed for better learning in programs and projects. Elsewhere, where funding is not tied, the constant pressure to demonstrate low overheads may also dissuade aid agencies from investing other resources necessary for effective organizational learning. Elsewhere still, competition for funding may induce fabrication of success stories and detract from constructive self-criticism and analysis, when it does not exacerbate the trend to "go cheap" and claim unrealistically low operating overheads.

\section{Thinking Strategically About Learning}

How responsibility for learning is structured reveals much about mind-sets and assumptions in an organization. Where efforts are made to mainstream it, responsibility will tend to be held by an individual post-holder at the middle-management level. Although this can give organizational learning a profile, legislating for learning is dangerous. Learning may be seen as the responsibility of an individual rather than as core to organizational practice and central to the organization's identity, values, culture, and worldview. Staff members who are held responsible for organizational learning will also often carry some anxiety about conveying clear statements to others (including senior managers). This could restrict the self-organizing potential of learning. If work on organizational learning is to be structured by the circumstances in which the work is to be performed (i.e., if form were to follow function), an organization may find it more useful to tend existing relationships, create spaces for experimentation and for conversations between people to grow across departmental boundaries, support informal links between and across organizations, offer opportunities and support for peer learning, and go where the energy is for as long as that is needed. ${ }^{5}$ (This entails offering incentives and rewards for learning.) Given

2 Sponsors of organizational learning tend to flag learning as a process. However, how then should one balance the evaluation of process and that of outcome? If learning is emphasized as a process, the fact that an organization is learning at all is, in itself, highly desirable. Conversely, if priority is given to effectiveness in accomplishing outcomes, learning will be ascribed less importance. Rationally, the way forward can only be found in the right mix of emphasis in various situations. For a note on the design and monitoring framework that recognizes the limitations of this planning tool and proposes improvements, see Serrat, O. 2008. Output Accomplishment and the Design and Monitoring Framework. Manila: ADB. Available: www.adb.org/documents/information/knowledge-solutions/output-accomplishment. pdf

3 Ramalingam, B., H. Jones, T. Reba, and J. Young. 2008. Exploring the Science of Complexity: Ideas and Implications for Development and Humanitarian Efforts. Working Paper 285. London: Overseas Development Institute. Available: www.odi.org.uk/publications/working papers/wp285.pdf. For a note on cultural theory and coevolution, see Serrat, O. 2001. Seeing the Forest and the Trees. Manila: ADB. Available: www.adb.org/documents/periodicals/ero/2001/seeing_forest.asp

4 ADB. 2007. Learning Lessons in ADB. Manila: ADB. Available: www.adb.org/documents/reports/learning-lessons-adb/strategicframework-2007-2009.asp

5 Interdependent inputs toward these would be a function of the nature of the task, the range of competencies required, the technology (to be) deployed, and the scale of operations. 


\section{Overcoming Roadblocks to Learning}

the unpredictable nature of learning, any strategy should be flexible, that is, not bound to specific outcomes. Investigations should start with an inquiry into the existing practices of staff members, the roadblocks that they face in context, and their assumptions about learning. From this, calculated responses might then be explored, experimented with, and learned from iteratively. This approach would shape strategic thinking. Figure 2 makes out eight means to focus on and reduce learning anxiety, each of which requires dedicated attention. ${ }^{6}$

Leadership is based on inspiration, not domination; on cooperation, not intimidation.

-William Arthur Wood

\section{The Role of Leadership}

More surprises occur as the result of a failure to act than as the result of a failure to see. Organizations have more to fear from not having strong leadership. It is the leader's responsibility to live the values the organization espouses,

set the right tone, and lead truly by example. Much as they must visibly promote the right culture by rewarding those who lead by example, leaders must strengthen or challenge patterns and norms that limit learning. Their reactions will be amplified by the position they carry. If they encourage staff members to take on work and then question their judgment, or constantly check on them, they will undermine the staff members and reduce creative thinking, innovation, and risk taking. Leaders must be aware that much value exists in communication, which allows leadership skills - good or bad - to show through. It is important that they seek formal and informal feedback on the impact of their gestures and that they be aware that second-order learning, by its very nature, may work against the improvement initiatives they promote. ${ }^{7}$ To recap, the principal role of leaders is to create the conditions within an organization through which staff members will first want to learn, then learn to learn, and finally internalize the habit of continuous learning. Figure 3 identifies broad measures that leaders can take to create the motive, means, and opportunity for learning.

Figure 2: Overcoming Learning Anxiety

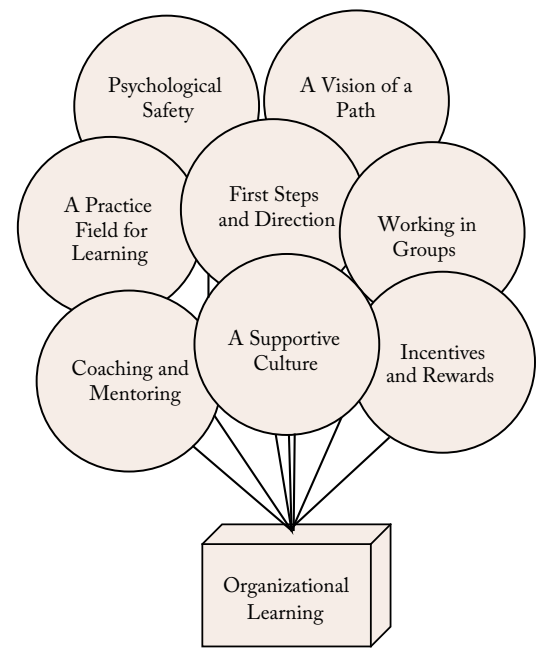

Source: Developed from Schein, E. 1995. Organizational and Managerial Culture as a Facilitator or Inhibitor of Organizational Transformation. Paper presented to the Inaugural Assembly of Chief Executive and Employers in Singapore. 29 June.

$6 \quad$ Blaming it on biological determinism, John Cacioppo explains that very early the brain exhibits a "negativity bias," meaning that it reacts with far more electrical activity to the stimuli of bad news than to good, and that this is seen at the early stages of information processing. Thus, our attitudes are more heavily influenced by downbeat than good news. See Ito, T., J. Larsen, K. Smith, and J. Cacioppo. 2002. Negative Information Weighs More Heavily on the Brain: The Negativity Bias in Evaluative Categorizations. In Cacioppo, J., et al., eds. Foundations in Social Neuroscience. Cambridge, Massachusetts: MIT Press.

7 For a note on the importance of management education and training, see Serrat, 0. 2000. Where Do We Stand on Bureaucratic Performance? Manila: ADB. Available: www.adb.org/documents/periodicals/ero/2000/performance.asp 


\section{Learning to Unlearn}

Unlearning may be the real challenge of learning. It may be simply characterized as the process of letting go of what is known, with openness and freshness of mind, to create fresh space for new learning to take root. It involves habits one has carried for many years. Learning is intimately part of the elaboration of a system - indeed almost synonymous with it. However, in discovering what must change, the greatest difficulties are often found in its structures and patterns. Consciously reading, assessing, and unlearning these will become fundamental. Ultimately, one may have to concede that it is not policies, strategies, processes, tools, methods, and approaches

Figure 3: Creating the Motive, Means, and Opportunity

Providing Models, Methods, and Support

- Ensure conceptual clarity

- Offer models and methods

- Support the competences necessary to learn

- Supply specialist assistance

- Invest financial resources

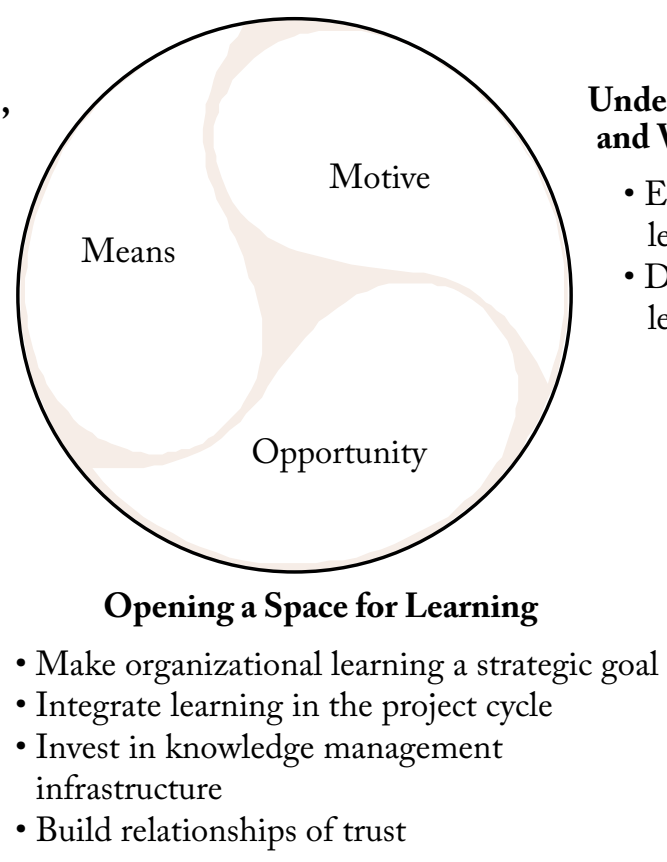

Source: Developed from Britton, B. 2005. Organizational Learning in NGOs: Creating the Motive, Means and Opportunity. International NGO Training and Research Center Praxis Paper No. 3. Available: www.intrac.org/docs.php/241/PraxisPaper3\%20 08\%20update.pdf

that define the core and quality of development practice but the past, present, and future, and the openness, judgment, intuition, creativity, integrity, and strength that one can muster to face these that do. In large bureaucratic organizations, unlearning also involves risk and requires psychological safety and the trust on which that rests, and both may be in short supply.

\section{Organizational Structure}

Although Liz Goold never mentioned hierarchical, centralized, or control-oriented structures, by all accounts, such roadblocks to organizational learning are formidable in most bilateral and multilateral agencies. Arguments against strong hierarchies are about the division of labor, office politics, and interpersonal relations. Hierarchical, centralized, and control-oriented organizations are inclined to separate thinking and acting, and entrust strategy and policy making to particular departments, offices, and senior managers. Top-down flows are inimical to teamwork within and across units. What is more, the structure fires up office politics: the priority of staff members is not learning but protecting or advancing their position, unit, or budget. To these, mastery of 
the operating system is of greater consequence than appreciating the context and probing the quality of a policy or operation. Conformity - not local accountability, flexibility, innovation, or critical reflection-is rewarded. To boot, field staff members find themselves at the bottom of the hierarchy, their views and interpretations overlooked or overruled. Capacity to learn is interrelated with power and authority in the sense that opportunity (time, space, and priority) to learn depends on where one stands in the hierarchy.

\section{Knowledge Inaction}

Goold also omitted to mention the inadequacy of information systems. Information overload ${ }^{8}$ is common in most aid agencies, but information and communication technologies for collaboration mechanisms, knowledge sharing and learning, and knowledge capture and storage are underdeveloped, under-resourced, or inefficient in all but a few. ${ }^{9}$ There is a problem, then, with identifying, creating, storing, sharing, and using quality data and information - synonymous with poor knowledge management. Bottom-up, formal routine reporting in hierarchical organizations has limited learning value. The emphasis is on outputs; accomplishments, not problems, are brought to light; time frames are too short. Reporting is seen as an obligation rather than an opportunity for ongoing, collective, interactive, and inquisitive conversation and dialogue based on quality data and information. By poor knowledge management, hierarchical organizations create self-supporting systems of misinformation.

\section{False Images}

Moreover, development agencies may have fallen victim to the false portrayal of their work as quick and simple. Even now, the sometimes surreal expectations of taxpayers continue to be fueled by annual reports highlighting success stories. Despite the high level of uncertainty of development work, there is pressure to be able to predict, if not appear infallible. In opposition, critics argue that development agencies have failed profoundly. With better public education work, development agencies can generate a more insightful understanding of the complexity of the work with which they are tasked (or task themselves). ${ }^{10}$

\section{(Lack of) Penalties for Not Learning}

Additionally, the absence of a market test for aid agencies removes the discipline that forces a business to change its ways or go bankrupt. They do not have profit margins, which ultimately depend on client interest and satisfaction. (In quite opposite ways, the beneficiaries of development programs and projects often have little voice and choice.) Therefore, aid agencies are tasked with measuring the larger part of their own performance (notwithstanding the small share of operations examined by independent evaluation) and, in so doing, downplay problems and failures. None of this, however, offers a good excuse for not learning; on the contrary, such arguments underscore learning as a necessity and priority. However, sadly, the judgment that an avoidable mistake in development work has been committed cannot always be argued beyond reasonable doubt - this does not ease the formulation of penalties for not learning, at least not immediately. Additionally, if indulgence for learning lessons were not granted and fair penalties for avoidable mistakes were formulated, how much time should one wait before witnessing improvements in performance at individual, team, cross-functional, operational, and strategic levels?

8 The exception is baseline data and information, which are critical to track progress and make changes if necessary during implementation of an operation, and to monitor and report on its contributions to outcomes.

9 Auditing the Lessons Architecture shows with a real-life example how a survey of perceptions conducted in 2007 provided entry points against which the Operations Evaluation Department (now the Independent Evaluation Department) in the Asian Development Bank can take measures to tie in with audiences in these areas. See ADB. 2008. Auditing the Lessons Architecture. Manila: ADB. Available: www.adb.org/documents/studies/auditing-lessons-architecture/in371-07.asp

10 For a note on realigning brands, defusing threats, and reperceiving social responsibility, see Serrat, O. 2001. International Organizations in the Globalized Economy. Manila: ADB. Available: www.adb.org/documents/periodicals/ero/2001/ international_organizations.asp 
Multiplying Agendas. The combined efforts of shareholders and (advocacy) nongovernment organizations to make aid agencies do a better job of development (by their criteria) tie them down with procedural requirements and prompt them to expand agendas to build coalitions of support. The circle is vicious; promises are not met, and these parties ratchet up requirements with tighter audits of compliance and the instigation of penalties for noncompliant staff members. In situations of no budgetary growth, the broadening scope of work puts staff members in a bind and undermines (when it does not prevent) learning. Conversely, growing operating costs may reduce demand from borrowing governments.

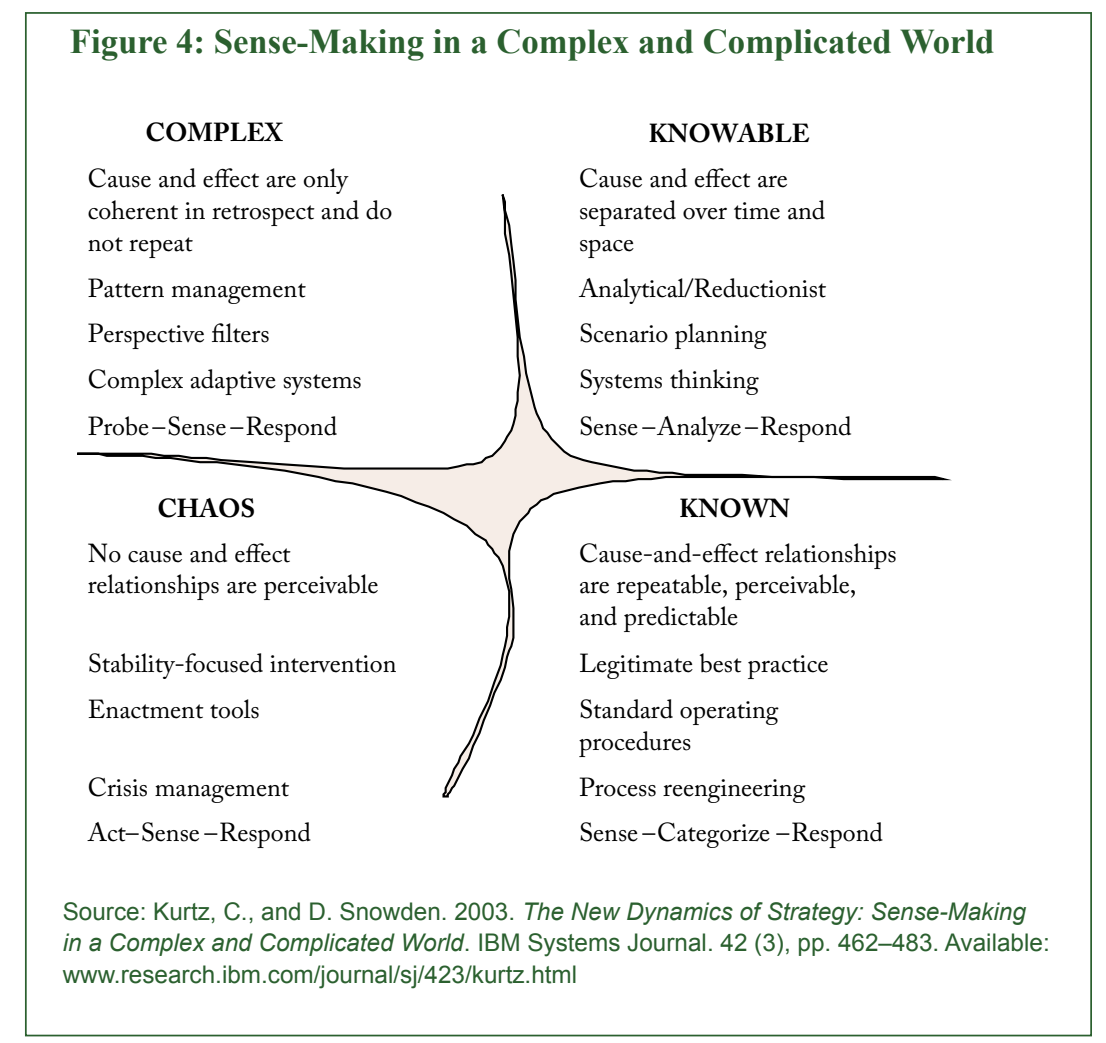

\section{Exclusion}

Development agencies recruit professional staff members from the international market and local staff members from applicants residing in duty station countries. It cannot be assumed that they share the same space for learning. In 2003, a study ${ }^{11}$ of the humanitarian sector found that international staff members accessed about 10 times more explicit knowledge assets from their organizations than their national counterparts. International staff members also attended meetings at approximately 10 times the rate of national staff members. Thus, how national staff members learn and are assisted in their learning and development is of central importance to the effectiveness of their agencies. Conversely, their importance as sources of "real" knowledge (including history) and their ability to approach things the right way are undervalued if not ignored. Only rarely are they seen as worthy of investment, supported, or given incentives. This waste of key knowledge assets is compounded by the fact that professional staff members characteristically move on when projects and programs end.

11 Active Learning Network for Accountability and Performance (ALNAP) in Humanitarian Action. 2004. Learning by Field Level Workers. In ALNAP Review of Humanitarian Action in 2003. London. Available: www.odi.org.uk/alnap/publications/rha2003/ pdfs/fch201bl.pdf 


\section{Overcoming Roadblocks to Learning}

\section{Complexity}

Cultural bias suggests why development aid follows a linear approach to achieving outputs and outcomes. That approach is guided by business processes (and associated compliance standards) applied with limited and out-of-date insights on dynamic operational contexts. Any planning process is based on assumptions ${ }^{12}$ - some will be predictable, others wishful. If the assumptions are based on invalid theories of change (including cause-andeffect relationships) and on inappropriate tools, methods, approaches, and procedures derived from those, development agencies will jeopardize the impacts that they seek to realize. Yet the cultural perspective draws insufficient conclusions about what complexity thinking should mean for development interventions. How might emerging insights from the complexity sciences and systems thinking, combined with field practice, systemically (rather than through a patchwork approach) reshape assumptions about the design of development assistance, improve

I know that most men, including those at ease with problems of the greatest complexity, can seldom accept even the simplest and most obvious truth if it be such as would oblige them to admit the falsity of conclusions which they have delighted in explaining to colleagues, which they have proudly taught to others, and which they have woven, thread by thread, into the fabric of their lives. reading of signals, and foster appropriate adapting of actions? What might be the implications of a shift from compliance with external standards to investing in capacities for navigating complexity? Figure 4 portrays a framework to help make sense of a range of unspecified problems, preferably collectively. The framework has five domains, four of which are named, and a fifth central area, which is the domain of disorder. The right-hand domains are those of order; the left-hand domains are those of un-order.

\section{Further Reading}

ADB. 2007. Learning Lessons in ADB. Manila: ADB. Available: www.adb.org/documents/reports/learninglessons-adb/strategic-framework-2007-2009.asp

- 2009. Learning for Change in ADB. Manila. ADB.

\section{For further information}

Contact Olivier Serrat, Head of the Knowledge Management Center, Regional and Sustainable Development Department, Asian Development Bank (oserrat@adb.org).

12 Cynthia Kurtz and David Snowden identified three basic, universal assumptions prevalent in organizational decision support and strategy: assumptions of order, of rational choice, and of intent. See Kurtz, C., and D. Snowden. 2003. The New Dynamics of Strategy: Sense-Making in a Complex and Complicated World. IBM Systems Journal. 42 (3), pp. 462-483. Available: www. research.ibm.com/journal/sj/423/kurtz.html 


\section{Knowledge
Solutions}

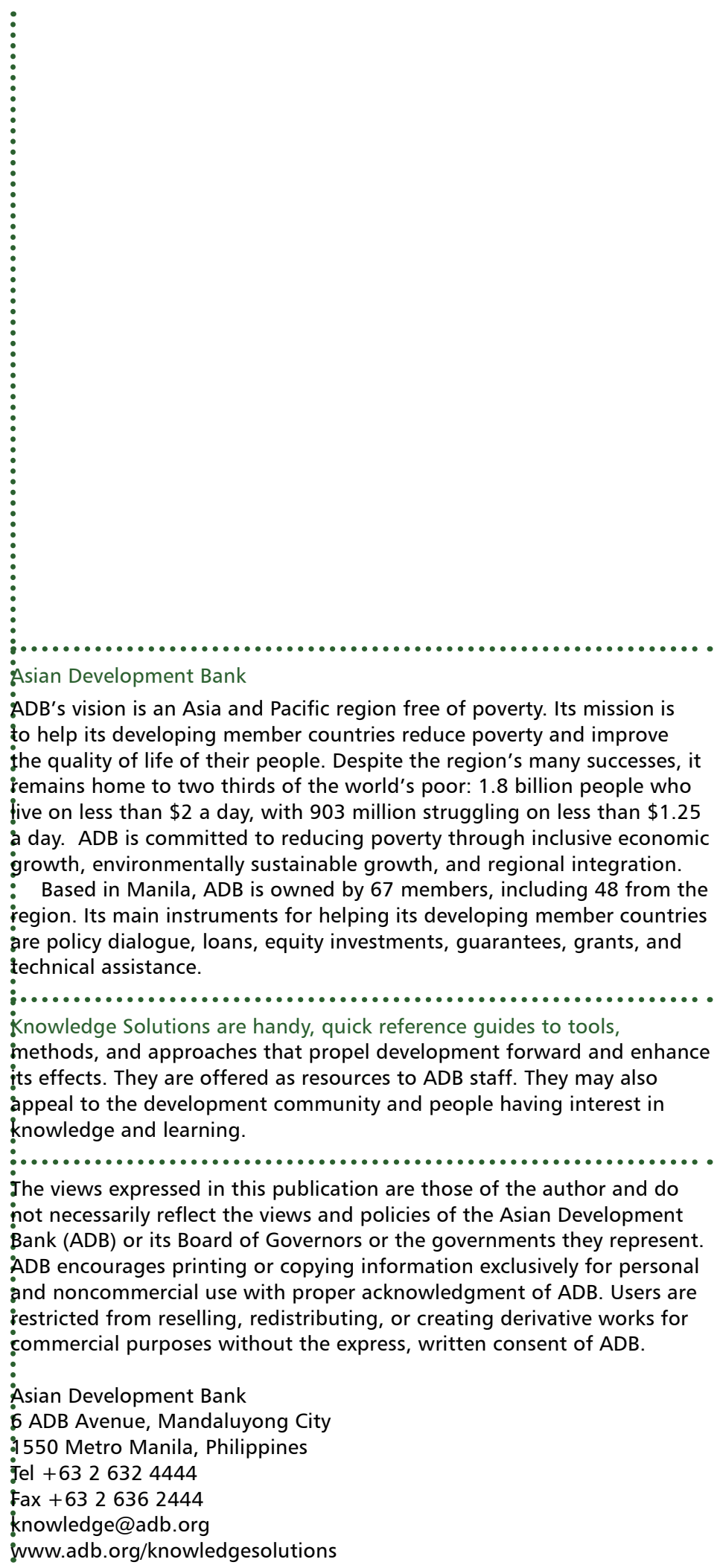

